\title{
STUDIES ON CAMPYLOBACTER SPUTORUM SUBSPECIES MUCOSALIS
}

\author{
G. H. K. Lawson, A. C. Rowland and L. Roberts \\ Department of Veterinary Pathology, University of Edinburgh Veterinary Field Station, \\ Easter Bush, Roslin, Midlothian EH25 9RG
}

\section{Plate XII}

IN a previous communication, we have described the principal characters of a number of strains of Campylobacter sputorum originating from the intestinal mucosa of cases of porcine intestinal adenomatosis (Lawson, Rowland and Wooding, 1975a). The number of organisms examined in our initial work was necessarily restricted.

In an examination of 10 normal pigs, it was not possible to recover $C$. sputorum from the intestinal sites at which adenomatosis commonly occurs or from the intestinal contents (Lawson and Rowland, 1974).

Porcine intestinal adenomatosis (PIA), necrotic enteritis (NE), regional ileitis (RI) and proliferative haemorrhagic enteropathy (PHE) all have a common morphological basis; organisms that could not be differentiated from C. sputorum subspecies mucosalis have been isolated from pigs with the first three of these conditions (Rowland and Lawson, 1975). The present communication compares, in detail, mucosalis strains from adenomatous tissue with strains isolated from pigs with NE or RI and also from the oral cavity of pigs (Lawson, Rowland and Roberts, 1975b). To date, we have been unable to obtain fresh material for bacteriological examination from cases of PHE.

\section{MATERIALS AND METHODS}

Isolation procedures. These were the same as described previously (Lawson and Rowland, 1974). Dilutions of homogenised mucosa were prepared in Reinforced Clostridial Medium (RCM; Oxoid Ltd) and dilutions of chyme in phosphate-buffered saline (PBS). Volumes $(0.1 \mathrm{ml})$ were plated on Columbia Agar (Oxoid CM331) with $7 \%$ horse blood and on a selective medium. The latter comprised a nutrient base (Oxoid CM271) with the addition of horse blood $5 \%(\mathrm{v} / \mathrm{v})$, brilliant green (G. T. Gurr Ltd) 1 in 60000 and novobiocin (Upjohn Ltd, Crawley, Sussex) $5 \mu \mathrm{g}$ per ml. The presence of brilliant green in solid media reduces the viable counts of $C$. sputorum subsp. mucosalis obtained whilst permitting the resistant colonies of this organism to grow freely. Stock solutions of brilliant green and representative batches of media were tested to confirm that the reduction in viable counts of broth cultures plated on the selective medium did not exceed $1 \log _{10}$ dilution in comparison with blood agar.

Plates were incubated at $37^{\circ} \mathrm{C}$ in a microaerophilic atmosphere (Lawson and Rowland, 1974) and examined daily. Total colony counts were recorded at the time representative

Received 1 July 1975; accepted 29 Sept. 1975.

J. MED. MICROBIOL.-VOL. 9 (1976) 
subcultures were made. Subcultures from primary colonies were examined for pigment and in gram-stained smears, slide-catalase tests and slide-agglutination tests with mucosalis " $\mathrm{OH}$ " antisera. Yellow-pigmented, catalase-negative vibrios reacting in slide agglutination tests were considered to be mucosalis and the viable counts were estimated from these results. Representative strains from each site of isolation were then arbitrarily selected and examined in detail.

Strains were obtained from saliva by the method of Lawson et al. (1975b).

Electron microscopy. Tissues were prepared and examined as described by Rowland and Lawson (1974). Photographs of adenomatous cells were studied and bacteria showing evidence of division were recorded.

\section{Biochemical tests}

The method of testing for the ability of the organism to grow in the presence of inhibitory substances was the replicate-plating method used previously (Lawson et al., 1975a). Tests for reduction of nitrate and nitrite, and for the production of catalase and hydrogen sulphide were also as described by Lawson et al. (1975a).

\section{Serological tests}

Antisera. The preparation of antisera in rabbits against whole-cell (" $\mathrm{OH}$ ") vaccines has been described (Lawson and Rowland, 1974). Antisera were also prepared against autoclaved suspensions of organisms (" $O$ "). These designations should not be taken to imply a correspondence with similarly named classes of antigens in other bacterial species. Bacteria for the preparation of $\mathrm{O}$ antisera were obtained from 48-h growth on Columbiablood-agar slopes, washed once by centrifugation and resuspension in distilled water. The final suspension in distilled water was autoclaved for $1 \mathrm{~h}$ at $121^{\circ} \mathrm{C}$, then centrifuged, and the deposit resuspended in $\mathrm{NaCl} 0.4 \%(\mathrm{w} / \mathrm{v})$; merthiolate was added to a final concentration of 1 in 10000 . The injection schedule was as for the production of the $\mathrm{OH}$ antisera.

Agglutination tests. $\mathrm{OH}$ suspensions were prepared from 48-h cultures on Columbiablood-agar slopes (Lawson and Rowland, 1974) and stored as concentrated antigen at $5{ }^{\circ} \mathrm{C}$ in formal saline containing $\mathbf{0 . 1 2 \%}$ formaldehyde. Bacteria for $\mathrm{O}$ suspensions were harvested in distilled water and centrifuged at 4000 r.p.m. for $30 \mathrm{~min}$; the deposit was resuspended in distilled water, held for 1 or $2 \mathrm{~h}$ at $75^{\circ} \mathrm{C}$, or $100^{\circ} \mathrm{C}$, or for $1 \mathrm{~h}$ at $121^{\circ} \mathrm{C}$, cooled, centrifuged and resuspended in $\mathrm{NaCl} 0.4 \%(\mathrm{w} / \mathrm{v})$. Immediately before use, the antigen preparations were adjusted to a standard density (approximately equal to that of Brown's opacity tube no. 2) by means of a nephelometer, the $\mathrm{OH}$ suspensions being diluted with $\mathrm{NaCl} 0.75 \%(\mathrm{w} / \mathrm{v})$ and the $\mathrm{O}$ suspensions with $\mathrm{NaCl} 0.4 \%$ (w/v).

$\mathrm{OH}$-agglutination tests were placed briefly in a $56^{\circ} \mathrm{C}$ water bath to ensure mixing before being incubated overnight at $37^{\circ} \mathrm{C}$. O-agglutination tests were incubated at either $37^{\circ} \mathrm{C}$ or $56^{\circ} \mathrm{C}$.

Alternative methods of preparing these antigens proved unsatisfactory; heat-treated formalinised antigens, and antigens treated with ethanol at $45^{\circ} \mathrm{C}$ were unstable in suspension. The preservation of $\mathrm{O}$ antigens with merthiolate appeared to reduce their reactivity progressively to $\mathrm{O}$ antisera.

Slide-agglutination tests. These were done with the surface growth from solid media suspended in saline and antisera preserved with glycerine $30 \%(\mathrm{v} / \mathrm{v})$.

Absorption. After appropriate dilution with $\mathrm{NaCl} 0.75 \%(\mathrm{w} / \mathrm{v})$, the serum was added to the absorbing antigen; the suspension was agitated for $1 \mathrm{~h}$ at room temperature and then centrifuged. Titrations of the absorbed and unabsorbed antisera were carried out in parallel.

Fluorescent staining. Goat anti-rabbit serum was purified by precipitation with rivanol (Mostratos and Beswick, 1969) and conjugated with fluorescein isothiocyanate (FITC) according to Nairn (1964). Saline suspensions of the organisms were air-dried on formalinised gelatin-treated slides and were stained by an indirect technique. 


\section{RESULTS \\ Quantitative studies in pigs}

Enumeration of the organism is complicated by the fact that viable counts on media containing novobiocin and brilliant green are lower than counts on non-selective media. This occurs not only with laboratory cultures but also when bacteria are isolated directly from intestinal adenomatous tissue. It would be preferable to make counts of the organism on non-inhibitory media, but the advantages of selective media outweigh their disadvantages. Comparisons of the numbers of organisms in tissues were accordingly made from counts on selective media. These counts were invariably lower than counts obtained on non-inhibitory media but were within $1 \log _{10}$ dilution of the latter.

Although tissue dilutions were prepared in RCM, chyme was diluted in PBS (see Methods). Comparisons of dilutions of chyme in RCM and PBS from cases of porcine intestinal adenomatosis (PIA) indicated that these yielded comparable numbers of organisms.

In table I we present the results of quantitative studies on eight pigs with histologically confirmed intestinal adenomatosis. Irrespective of whether the lesion was in the mucosa of the small or large intestine, large numbers of $C$. sputorum subsp. mucosalis were isolated, and the number of organisms correlated well with the site of occurrence of the predominant mucosal lesion. When only the colonic mucosa was adenomatous, infection was restricted mainly to the affected tissue and the organism could not be isolated from the normal small-intestinal mucosa in two of such animals. When wall and chyme were sampled in parallel, the numbers of mucosalis present in the mucosa were invariably the greater. We were able to isolate the organism from some but not all of a small number of faecal samples.

TABLE I

Number of Campylobacter sputorum subsp. mucosalis isolated from pigs in relation to the presence of lesions of intestinal adenomatosis

\begin{tabular}{|c|c|c|c|c|c|c|}
\hline \multirow{2}{*}{$\begin{array}{c}\text { Animal } \\
\text { no. }\end{array}$} & \multicolumn{6}{|c|}{ Viable count* (per $g$ wet weight) from } \\
\hline & $\begin{array}{l}\text { mid ileum: } \\
\text { mucosa }\end{array}$ & $\begin{array}{l}\text { lower ileum: } \\
\text { mucosa }\end{array}$ & $\begin{array}{l}\text { lower ileum: } \\
\text { chyme }\end{array}$ & $\begin{array}{l}\text { colon: } \\
\text { mucosa }\end{array}$ & $\begin{array}{l}\text { colon: } \\
\text { chyme }\end{array}$ & faeces \\
\hline $\begin{array}{r}614 / 73 \\
5 / 74 \\
60 / 74 \\
101 / 74 \\
489 / 74 \\
604 / 74 \\
632 / 74 \\
106 / 75\end{array}$ & $\begin{array}{c}\ldots \\
\ldots \\
\ldots \\
\ldots \\
\ldots \\
\ldots \\
6 \cdot 20 \times 10^{4} \\
\text { NR }\end{array}$ & $\begin{array}{c}3.80 \times 10^{3} \\
\text { NR } \\
\text { NR } \\
3.06 \times 10^{3} \\
1.00 \times 10^{5} \\
\mathbf{9 . 1 5} \times 10^{4} \\
\mathbf{8 . 9 5} \times \mathbf{1 0}^{6}\end{array}$ & $\begin{array}{c}\ldots \\
\ldots \\
\ldots \\
\ldots \\
\ldots \\
\cdots \\
\ldots \\
4 \cdot 45 \times 10^{6}\end{array}$ & $\begin{array}{c}\mathbf{3 . 2 0} \times \mathbf{1 0 6} \\
\mathbf{8} \cdot \mathbf{4 0} \times \mathbf{1 0 6} \\
\mathbf{2 . 1 6} \times \mathbf{1 0 6} \\
\mathbf{5 . 3 6} \times \mathbf{1 0 6} \\
\mathbf{2 . 4 6} \times \mathbf{1 0} \\
\mathbf{2 . 9 6} \times \mathbf{1 0} \\
\ldots \\
\ldots\end{array}$ & $\begin{array}{c}1.40 \times 10^{5} \\
2.10 \times 10^{5} \\
7.68 \times 10^{5} \\
1.06 \times 10^{6} \\
\text { NR } \\
1.60 \times 10^{5} \\
\ldots \\
\ldots\end{array}$ & $\begin{array}{c}\ldots \\
\dddot{\mathrm{NR}} \\
8.60 \times 10^{3} \\
\mathrm{NR} \\
\ldots \\
3 . \\
3.52 \times 10^{6}\end{array}$ \\
\hline
\end{tabular}

* On blood agar containing novobiocin and brilliant green.

$\ldots=$ Not examined; $\mathrm{NR}=$ mucosalis not isolated.

In bold type: tissue grossly and histologically adenomatous. 


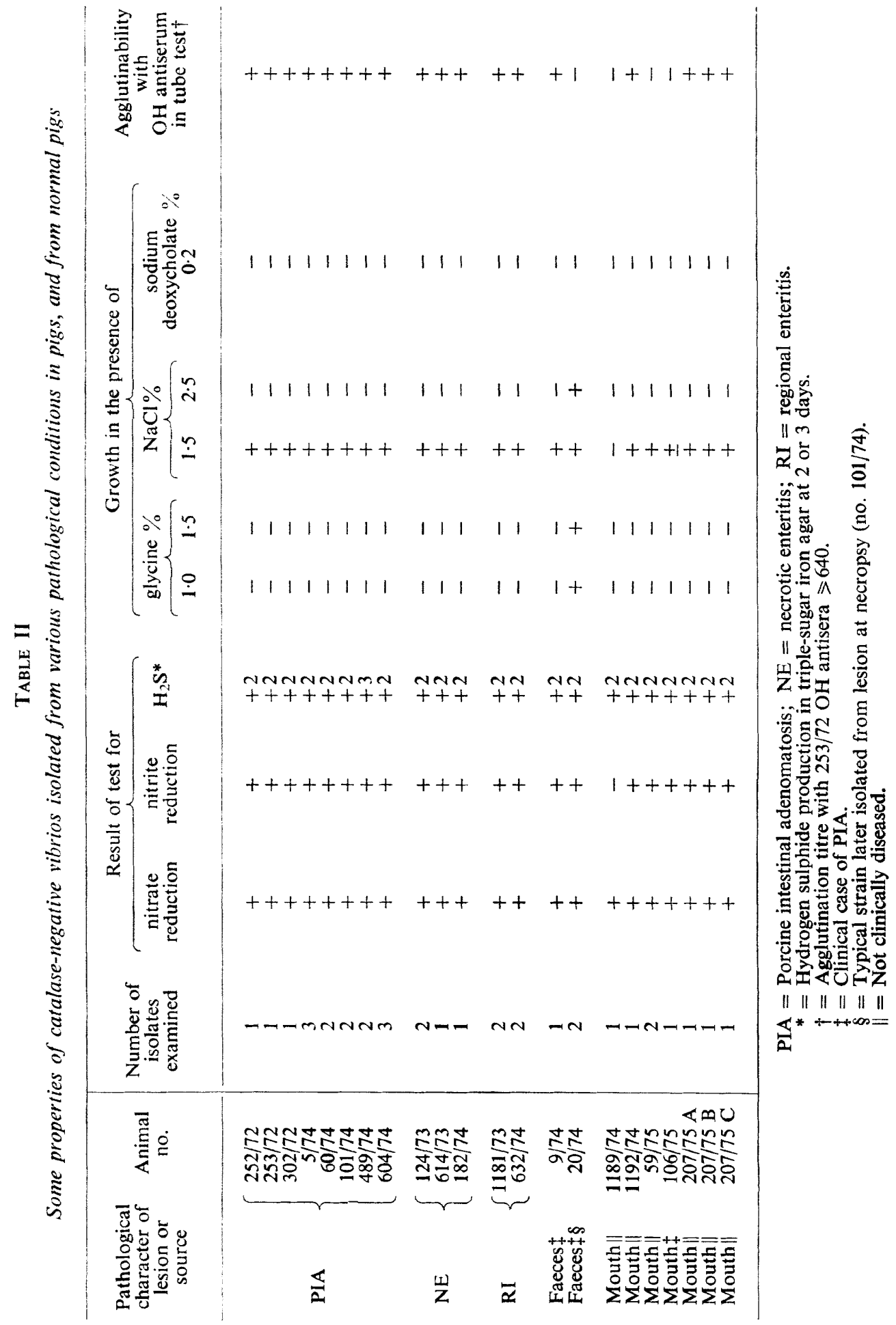




\section{Intracellular division}

The majority of bacterial profiles were incomplete or observed in transverse section. In sections from 12 pigs with intestinal adenomatosis, 225 full bacterial longitudinal profiles were present and clear evidence of septation was observed in three of these organisms (figure).

\section{Characterisation of strains}

Table II sets out the results of a series of laboratory tests on catalase-negative vibrios isolated from diseased and healthy pigs. The isolates from adenomatous tissue were a homogeneous group of organisms and were remarkably uniform when examined in the tests that had previously proved useful in identifying the subspecies. All the strains, whether isolated from cases of PIA, NE or RI, proved to have similar antigenic and biochemical properties. Typical mucosalis strains have also been isolated from the faeces of animals later shown to be affected with PIA. However, one strain of a catalase-negative vibrio, which differed antigenically and in tolerating higher concentrations of glycine and salt, was isolated from the faeces of an animal (no. 20/74) later shown to be affected with PIA; the same animal yielded a typical mucosalis strain from the affected mucosa at necropsy.

The population of mouth vibrios appears to be complex; many were biochemically identical with mucosalis, but others differed in their salt tolerance and ability to reduce nitrite. Whilst some mouth strains reacted with mucosalis $\mathrm{OH}$ antisera, and thus could not be differentiated from mucosalis, others failed to react at all in these tests. We should emphasise, however, that the predominant catalase-negative vibrios isolated from adenomatous lesions conformed to the description, both biochemically and antigenically, of mucosalis and that the slightly dissimilar (" atypical ") organisms have not been isolated from the adenomatous lesions.

Agglutination studies with $\mathrm{OH}$-antigen preparations in tubes. All three antisera prepared against the catalase-negative vibrios reacted to high titre with all the typical mucosalis strains tested. One serum was tested extensively and reacted with all the mucosalis strains, whilst failing to react at low dilution (20) with any of the 28 strains of catalase-positive vibrios tested. All three mucosalis antisera behaved similarly with the antigens tested and no attempt was made to test all strains with all the antisera. A series of eight antisera prepared against different types of catalase-positive Campylobacter coli (Lawson et al., 1975a) failed to react with any of the catalase-negative organisms tested. Examination of the " atypical " catalase-negative strains confirmed the differences noted in other tests in that they failed to react with mucosalis antisera. During these tests, the control antigen regularly reacted with its homologous antisera with the end-point fluctuating between 1 in 2560 and 1 in 10240 . Antigens prepared from strains from a case of NE (no. 124/73) were observed in a number of tests to react consistently to lower titre than strains from other animals, and for this reason an antiserum was prepared against a selected strain (no. 124/73 B4) from this animal. 
Agglutination studies with O-antigen preparations in tubes. When Oantisera were titrated against $\mathrm{OH}$-antigen suspensions there was no agglutination with either the homologous strain, other mucosalis strains, or the catalasepositive vibrios. Exposure of the bacteria to heat at $75^{\circ} \mathrm{C}$ for $1 \mathrm{~h}$ reduced the $\mathrm{OH}$ agglutinability of the organism without inducing agglutinability with $\mathrm{O}$-antisera. After exposure to $100^{\circ} \mathrm{C}$ for 1 or $2 \mathrm{~h}$, suspensions became partly agglutinable by $\mathrm{O}$ antisera and also reacted with $\mathrm{OH}$ antisera. Agglutination of such suspensions occurs at greater dilution if the tests are performed at $56^{\circ} \mathrm{C}$, but this was not our normal practice. Autoclaved suspensions reacted to high titre with homologous $\mathrm{O}$ antisera. These results are summarised in table III. All the mucosalis strains tested reacted with mucosalis $\mathrm{O}$ antisera, although there was some variation in the titre between different strains. Unlike the $\mathrm{OH}$ tests, $\mathrm{O}$ antigens of the catalase-positive $C$. coli strains did react with the mucosalis $O$ antisera to a low titre (40-640). Attempts to characterise possible shared and specific components present have proved unsuccessful to date.

Slide-agglutination studies. The slide-aggultination tests confirmed the results of the tube agglutination tests. Undiluted $O$ antisera did not react with young cultures of the mucosalis subspecies, although in older cultures some degree of agglutination may take place. $\mathrm{OH}$ antisera used in slide tests have never reacted with organisms that later proved atypical in tube tests, and $\mathrm{OH}$ antisera have never been observed to agglutinate strains that later proved to be catalase-positive vibrios.

Immunofluorescence studies. All the strains of the mucosalis subspecies tested have shown positive immunofluorescence with undiluted hyperimmune antisera. In contrast, only two of eight representative strains of $C$. coli showed

TABLE III

The effect of heat on the agglutinability of representative mucosalis strains

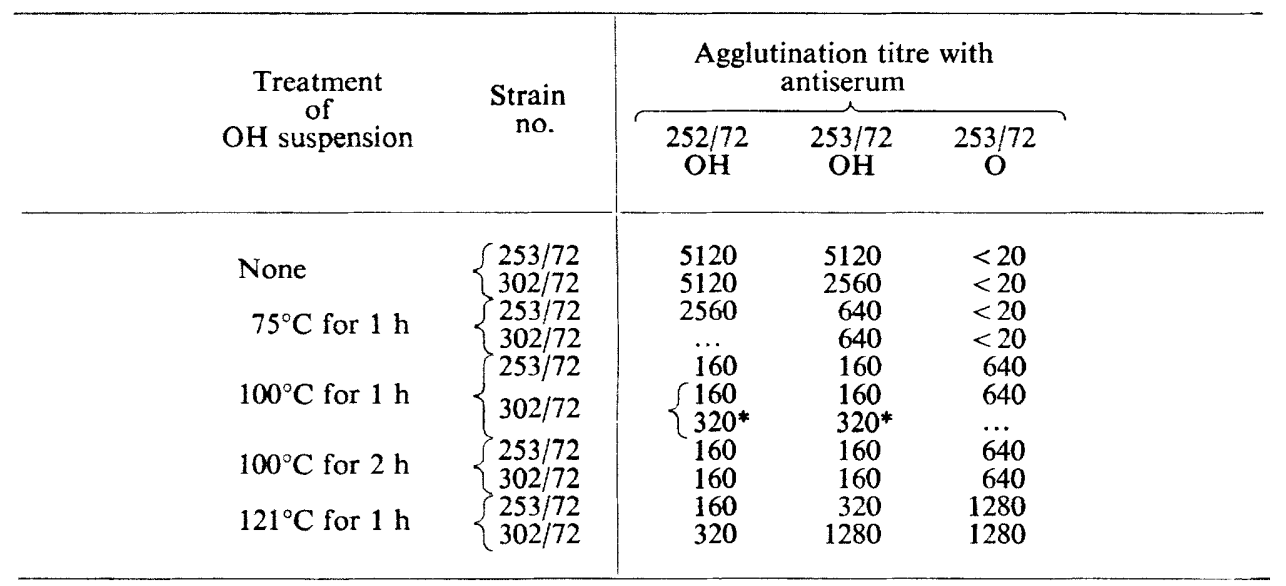

* Test carried out at $56^{\circ} \mathrm{C}$.

$\ldots$. Not done. 
CAMPYLOBACTER SPUTORUM SUBSPECIES MUCOSALIS

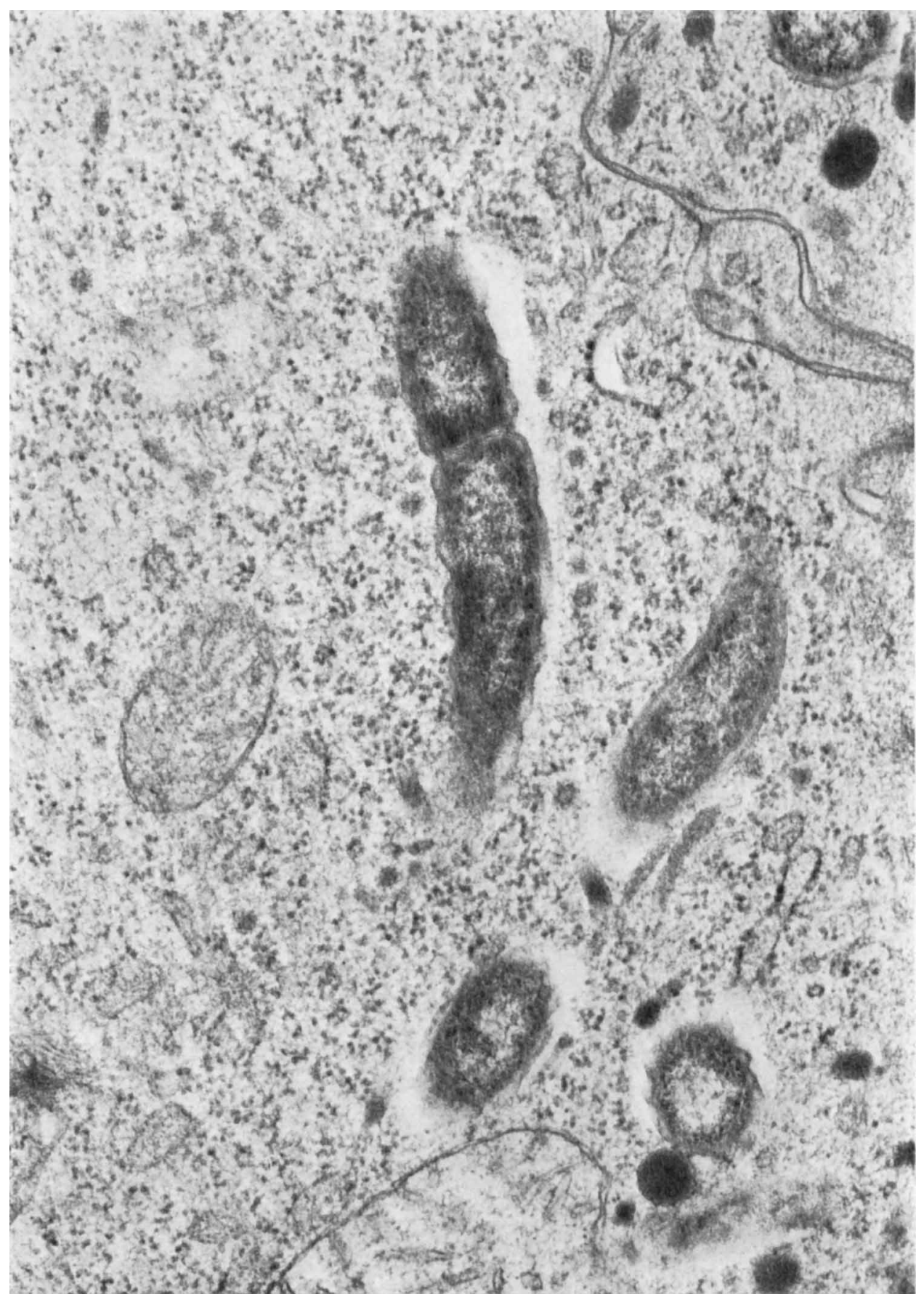

FIGURE.-Adenomatous epithelial cell containing intracellular bacteria, one of which shows septate division. Uranyl acetate and lead citrate. Electronmicrograph. $\times 60000$. 
any evidence of fluorescence with undiluted antisera and this was lost when the serum was used at a dilution of 1 in 10. All the mucosalis strains tested reacted at a dilution of 1 in 20 and homologous strains reacted at a serum dilution of 1 in 80.

Absorption experiments. These experiments have demonstrated that the surface antigens of the subspecies are complex in character and that the reactivity of strains with a single unabsorbed antiserum is dependent on a number of antigenic factors, all of which need not be present for the antiserum to react at dilutions approaching its maximum titre.

Absorption has demonstrated that strain 252/72 has a surface factor shared by no. 302/72 but not present in no. 253/72. Similarly, strains $253 / 72$ and $124 / 73$ B4 have a factor not present in no. 302/72, and strain 124/73 B4 has a factor not present in the other three strains. A simplified antigenic analysis of these strains is as follows.

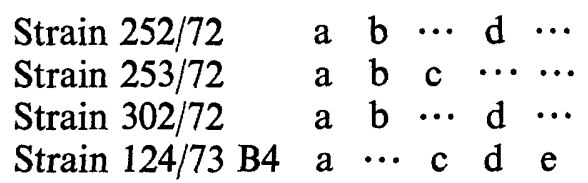

A summary of the absorption experiments is given in table IV.

\section{DisCussion}

These studies confirm that organisms with essentially similar characteristics may be isolated from the affected intestinal mucosa of pigs with the conditions of PIA, NE or RI. The latter two conditions show varying amounts of the remaining mucosa to be adenomatous, and it has been suggested (Rowland and Lawson, 1975) that in certain cases PIA may precede either NE or RI.

\section{TABLE IV}

Serum titres before and after absorption of mucosalis antisera by various antigens

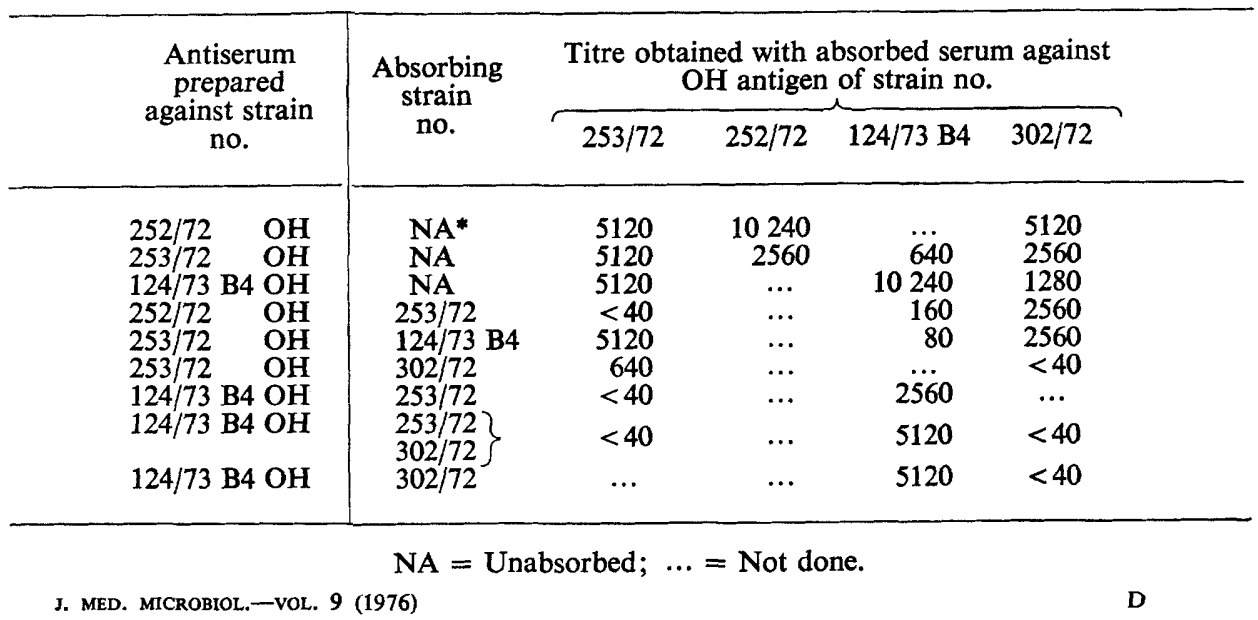


In pigs with PIA, the greatest concentrations of C. sputorum subsp. mucosalis occur in association with the adenomatous tissues; the areas of normal intestinal mucosa present in adenomatous cases do not harbour the organism, which is present in larger numbers in the affected tissue than in the intestinal lumen. We have no direct evidence to indicate that the intracellular vibrio brings about the adenomatous change. However, it seems possible that either (1) the epithelial cell is preferentially parasitised by the bacteria and that a change is subsequently induced in the gland cells, or (2) that adenomatous epithelium developing as a result of some other influence specifically phagocytoses this organism from a postulated luminal population. The first proposition is supported by the presence of dividing organisms within the cell cytoplasm and by the lack of morphologically similar bacteria adjacent to the surface of the adenomatous cell (Rowland and Lawson, 1974). A logical concept based on these observations is that immature epithelial cells become infected by the organisms, that these persist intracellularly by multiplying in the dividing cells, and that infection thus spreads within the epithelium.

The present studies confirm the presence of $C$. sputorum subsp. mucosalis and other catalase-negative vibrios in small numbers in the oral cavity of pigs. All the latter organisms differ serologically and some differ biochemically from mucosalis subspecies. We feel that at present nothing is to be gained by applying a specific epithet to these organisms and we retain the name mucosalis to identify the typical organisms isolated from adenomatous tissue, or serologically and biochemically identical organisms isolated from other sites.

Small but distinct antigenic differences exist between strains of the mucosalis subspecies. It is not clear at present whether these differences have any epidemiological significance or whether they merely indicate an antigenic shift related to host adaptation.

These results uphold and extend our opinion that the mucosalis strains form a distinct subspecies. One of our earlier strains has been deposited with the National Collection of Type Cultures as the neotype strain (C. sputorum subsp. mucosalis strain no. 253/72, no. NCTC11 000).

\section{SUMMARY}

Catalase-negative vibrios can be isolated in large numbers from the affected intestinal mucosa of pigs suffering from a range of porcine enteropathies in which the mucosa has an adenomatous component. These vibrios cannot be distinguished from strains of Campylobacter sputorum subsp. mucosalis. The resemblance between these bacteria strengthens the case already made on morphological evidence that these enteropathies have a common origin.

Catalase-negative vibrios have also been isolated from the mouth and faeces of pigs. Some of these conform to the criteria established for the mucosalis subspecies but others can be differentiated from it.

An antigenic analysis shows that strains of the mucosalis subspecies are closely related antigenically, but that differences may allow separation of strains. 
This work was in part supported by a grant from the Wellcome Trust. It is a pleasure to acknowledge the technical assistance of Miss P. Wooding and Miss M. Mitchell.

\section{REFERENCES}

Lawson, G. H. K. AND Rowland, A. C. 1974 . Intestinal adenomatosis in the pig: a bacteriological study. Res. vet. Sci., 17, 331.

Lawson, G. H. K., Rowland, A. C. AND RoBerts, L. 1975b. Isolation of Campylobacter sputorum subsp. mucosalis from the cavity of pigs. Vet. Rec., 97, 308.

Lawson, G. H. K., Rowland, A. C. AND Wooding, P. 1975a. The characterisation of Campylobacter sputorum subspecies mucosalis isolated from pigs. Res. vet. Sci., 18, 121.

Mostratos, A. AND Beswick, T. S. L. 1969. Comparison of some simple methods of preparing $\gamma$-globulin and antiglobulin sera for use in the indirect immunofluorescence technique. J. Path., 98, 17.

NAIRN, R. C. 1964. Fluorescent protein tracing, 2nd ed., Edinburgh and London, p. 19.

Rowland, A. C. AND Lawson, G. H. K. 1974. Intestinal adenomatosis in the pig: immunofluorescent and electron microscopic studies. Res. vet. Sci., 17, 323.

Rowland, A. C. and Lawson, G. H. K. 1975. Porcine intestinal adenomatosis: a possible relationship with necrotic enteritis, regional ileitis and proliferative haemorrhagic enteropathy. Vet. Rec., 97, 178. 